\title{
AUTO-HERMENÊUTICA EM ENTREVISTAS AUTOBIOGRÁFICAS
}

\section{PATRÍCIA CLAUDIA DA COSTA}

Universidade Federal de Viçosa

Este artigo analisa alguns "efeitos colaterais" provocados por entrevistas de natureza autobiográfica, tendo como base de dados 31 entrevistas, realizadas durante uma pesquisa sobre a trajetória de docentes universitários, e a "auto-hermenêutica" como noção norteadora. Trata-se de um tipo de processo reflexivo no qual o entrevistado elabora conteúdos que o levam a analisar sua trajetória, em uma dupla perspectiva: subjetivando as experiências que seleciona para relatar e objetivando a si próprio como sujeito socio-histórico. o resultado desse processo se manifesta na tomada de consciência sobre possibilidades e desafios - pessoais e profissionais, presentes ou previstos no porvir - o que, por sua vez, gera novas tomadas de posição do sujeito, enquanto agente social. O objetivo da análise, pautada na teoria bourdieusiana, é explicitar um dos aspectos da dimensão formativa das entrevistas, que se estruturam em temas essencialmente autobiográficos, no que tange à percepção dos entrevistados sobre fatos, valores, conhecimentos, experiências e sentidos, que afloram nos discursos em situação de entrevista. Concluise que o ato de falar de si corresponde a uma oportunidade epistêmica de feições hermenêuticas, à medida que o sujeito reconhece a própria capacidade de reelaborar alguns aspectos de sua trajetória, inclusive com vistas a reordenar seus rumos, com base na reflexão sobre as condições reconhecidas.

Palavras-chave: Entrevista autobiográfica. Auto-hermenêutica. Pierre Bourdieu.

\section{ABSTRACT SELF-HERMENEUTIC IN AUTOBIOGRAPHICAL}

\section{INTERVIEWS}

This article analyzes some "effects" caused by interviews of autobiographical nature, based on 31 interviews, carried out in the context of a research on the trajectory of university teachers, using the "self-hermeneutic" as guideline notion. This is a type of reflective process in which the interviewee elaborates contents that makes 
himself analyze his own trajectory in a double perspective: subjectifying the experiences that he selects for reporting and objectifying himself as a socio-historical subject. The result of this process is manifested in the awareness about the possibilities and challenges - personally and professionally, presented or provided in the upcoming events - that, in turn, generates new positions while social agent. The aim of the analysis, based on Bourdieu's theory, is to clarify one of the aspects of the formative dimension of the interviews that are structured according autobiographical themes, taking in regard the perception of the interviewee about facts, values, knowledge, experience and meanings that emerge in speeches during and after the interview. It concludes that the act of speaking of ourselves corresponds to an opportunity epistemic with hermeneutical characteristics, as the subject recognizes the ability to redraft some aspects of his trajectory, including views to reorder the directions, based on the reflection about the recognized conditions within.

Keywords: Autobiographical interview. Self-hermeneutic. Pierre Bourdieu.

\section{AUTO-HERMENÉUTICA EN ENTREVISTAS}

\section{AUTOBIOGRÁFICAS}

Este artículo analiza algunos "efectos" provocados por entrevistas de carácter autobiográfico, teniendo como base 31 entrevistas, realizadas en el contexto de una investigación sobre la trayectoria de los profesores universitarios, y la "auto-hermenéutica" como concepto rector. Este es un tipo de proceso de reflexión que permite al entrevistado la elaboracion de contenidos para analizar su trayectoria en una doble perspectiva: subjetivando experiencias que selecciona para informar y apuntando a sí mismo como un sujeto socio-histórico. El resultado de este proceso se manifiesta en la conciencia acerca de las posibilidades y retos, personales y profesionales, presentes o previstos en el futuro - que, a su vez, genera nuevas posiciones mientras agente social. El objetivo del análisis, basado en la teoría bourdieusiana, es aclarar uno de los aspectos de la dimensión formativa de las entrevistas que se estructuran como temas esencialmente autobiográficos, por lo que se refiere a la percepción de los entrevistados acerca de los hechos, los valores, los conocimientos, la experiencia y los sentidos que surgen en los discursos en situación de entrevista. Se concluye que el acto de hablar de sí mismo corresponde a una oportunidad epistémica de carácter hermenéutico, en la medida en que el sujeto reconoce la posibilidad de reformular 
algunos aspectos de su trayectoria, incluso con vistas a reordenar las direcciones sobre la base de la reflexión acerca de las condiciones reconocidas.

Palabras clave: Entrevista autobiográfica. Auto-hermenéutica. Pierre Bourdieu.

A lembrança da vida da gente se guarda em trechos diversos, cada um com seu signo e sentimento, uns com os outros acho que nem não se misturam.

João Guimarães Rosa (2001)

\section{Contexto da pesquisa}

As análises que compõem este artigo dão continuidade ao esforço reflexivo de compreender, à luz da teoria do sociólogo francês Pierre Bourdieu, as potencialidades do uso de entrevistas qualitativas, no âmbito da Sociologia da Educação, quando estas se pautam na noção de trajetória, tendo em vista elucidar fenômenos que se inscrevem nas histórias de vida dos sujeitos. Tal esforço foi inicialmente discutido enquanto realizava entrevistas para minha pesquisa de doutorado. Naquele momento, interessava-me verificar a pertinência de conciliar a teoria bourdieusiana com o uso de material biográfico (COSTA, 2015). Tendo finalizado a coleta de dados e imersa na tarefa de analisá-los para fins de escrita, surgiu a necessidade de discutir alguns achados surpreendentes que fogem ao escopo específico da pesquisa.

Resumidamente, a pesquisa teve como objeto os condicionantes sociais das trajetórias formativas e profissionais de docentes que: (i) ingressaram no corpo docente de uma universidade federal, no âmbito dos programas

1 Trata-se de uma pesquisa sobre a reconfiguração do corpo docente das universidades federais brasileiras, no contexto da expansão da educação superior pública (período 2004-2014), desenvolvida no Programa de Pós-Graduação em Educação da Faculdade de Educação da Universidade de São Paulo (FEUSP), sob orientação do Prof. Dr. Afrânio Mendes Catani, aprovada pelo Parecer FE 049/2014 do Comitê de Ética da FEUSP e qualificada em junho de 2015. de expansão em curso a partir de 2004; e (ii) pertencem a famílias sem tradição de longevidade escolar e com baixos volumes de capital, sobretudo econômico e cultural. O referencial teórico-metodológico ancorou-se na sociologia relacional bourdieusiana e o principal objetivo foi desvelar os mecanismos de ação desses agentes, diferenciados por terem trilhado percursos escolares pouco prováveis para conduzir à "docência superior", e que incidem diretamente em mudanças significativas em uma cultura institucional compelida a transformarse pelas demandas da expansão universitária. Para alcançar tal objetivo, utilizou-se uma metodologia fundamentalmente qualitativa, que consistiu em análise documental, aplicação de questionário on-line, observação do local de trabalho e entrevista presencial com 31 docentes de cinco campi da Universidade Federal de São Paulo (Unifesp), no período de julho de 2014 a fevereiro de 2015, as quais passam a constituir o material a ser analisado nesta comunicação.

As entrevistas trataram de diversos aspectos das trajetórias de vida, com ênfase nas dimensões formativa e profissional, sendo os mais relevantes: situação familiar, escolarização, experiências culturais e sociais, influências na escolha profissional, experiências como estudante universitário, inserção profissional, atuação na Unifesp e impressões sobre questões controversas na instituição (critérios de produtividade, distinção por áreas de atuação, expansão universitária, greve das federais em 2012, eleição e atuação da última reitoria, perfis docentes e discentes). 
De acordo com a infraestrutura disponível em cada campus, as entrevistas foram concedidas nos mais diferentes locais. Entre as que se realizaram nas dependências institucionais, os espaços variaram entre: gabinetes e laboratórios, tanto individuais como coletivos, além de salas de aula, de gestão ou de reunião e até um refeitório. Entre os espaços externos ao ambiente universitário, houve encontros em uma livraria, na sede do sindicato dos docentes, na residência de dois docentes e em algumas cafeterias. A duração média das entrevistas foi de $1 \mathrm{~h} 30$, em sessão única, sendo que a mais curta durou 64 minutos e a mais longa, 3h50, totalizando 56 horas de gravação. Respeitando-se a negociação prévia, todos os sujeitos receberam a transcrição integral e tiveram a oportunidade de revisá-la e de solicitar supressões e acréscimos. Nove docentes fizeram uso dessa prerrogativa. As ocorrências mais frequentes incidiam sobre a exclusão de informações de caráter pessoal, reveladas na descontração experimentada na situação de entrevista, e, em segundo lugar, críticas a colegas e instituições. Poucos acréscimos foram feitos e resultaram de questionamentos que acompanharam o envio das transcrições para fins de complementação da coleta.

Nesse contexto investigativo, serão circunscritas e analisadas algumas manifestações discursivas, registradas durante a entrevista ou em interação posterior, que suscitam e alimentam a seguinte problematização: para além da colaboração entre pares, a concessão de uma entrevista pode provocar outros efeitos sobre o entrevistado? Se sim, quais seriam? Alguns desses efeitos apresentam alguma relação com a dimensão formativa da metodologia autobiográfica? Como? Na tentativa de elucidar essas questões, vale retroceder ao reconhecimento da importância do uso da noção de trajetória, que impulsionou todo o movimento de pesquisa, de modo a compreen- der como e por que a "auto-hermenêutica" se impõe como resposta adequada ao fenômeno observado.

\section{Da "ilusão biográfica" à "auto- hermenêutica"}

Como discutido por Costa (2015), a ideia de que Pierre Bourdieu rechaçava o uso de material empírico de natureza (auto)biográfica deve-se a um entendimento equivocado de sua crítica à ilusão retrospectiva finalista comum a relatos que expõem histórias de vida como se fosse possivel traçar a "história de uma vida", de maneira linear e causal. Em outros termos, Bourdieu criticou a pretensão teleológica, evidente em materiais biográficos que primam por expor a história individual de um sujeito, em termos de predestinação ou de dom, e que trata o conteúdo biográfico com um vetor único de causalidade. A pretensão teleológica, que funda e justifica a ilusão retrospectiva, desconsidera que cada sujeito está inscrito numa história social individual, condicionada por e reveladora de seu contexto de produção, e que o discurso do sujeito sobre essa história é sempre uma reconstrução a posteriori dos acontecimentos mais significativos que marcaram sua trajetória, resultado de uma seleção, raramente linear, do que pode ou merece ser contado.

A trajetória, portanto, corresponde ao transcurso mais autêntico da vida real, repleta de: multicausalidades, avanços, recuos, tropeços, encruzilhadas, bifurcações, ruas sem saída, atalhos, acidentes de percurso e tantos outros fatores que dispensam longas argumentações para que o leitor mais exigente se convença de que tentar apreender parte da complexidade que constitui uma trajetória individual é tarefa mais factivel, e intelectualmente honesta, do que buscar reconstituir a história de uma vida cujos sentidos são, muitas vezes, uma ficção 
de si, criada para mostrar como coerente uma história que reconfigura o real no ato mesmo de sua reconstituição. Certamente, para aqueles que se dedicam a pesquisar as representações dos sujeitos sobre suas histórias de vida, ou questões correlatas, o problema apontado por Bourdieu (1986) não chega a se constituir em um obstáculo metodológico e epistemológico. Pelo contrário, pode até ser tomado como o próprio objeto de estudo. No entanto, para as pesquisas que demandam informações autobiográficas que contribuam para esclarecer, por exemplo, fenômenos sociais, históricos ou antropológicos, o desprezo pela noção de trajetória em detrimento da adesão acrítica a um relato linear da "história de uma vida" pode se tornar um grande empecilho para a produção científica.

Convencida da importância de tratar as informações oferecidas pelos entrevistados como momentos de trajetórias, passiveis de sobreposição e desordenamento temporal, e não como etapas sucessivas da "história de como chegou até aqui", passei a me preocupar com as reações dos entrevistados, ao revelarem parte de suas vidas para uma pessoa completamente estranha, que, provavelmente, jamais reencontrariam, e cujo único propósito era extrair deles todos os indícios possíveis para elucidar sociologicamente como tais agentes se tornaram docentes, no contexto específico da expansão das universidades federais. Dito de outro modo, comecei a ouvir mais atentamente algumas declarações que apontavam efeitos da entrevista, pois extrapolavam meus objetivos como pesquisadora, estando relacionados a modos de percepção dos fenômenos de subjetivação e objetivação de si pelos próprios entrevistados durante sua participação na pesquisa. Com base nesses apontamentos, denominei de "auto-hermenêutica" o processo pelo qual o sujeito examina sua própria trajetória e descobre, por meio da interpretação pessoal acerca dos fatos relatados, aspectos e sentidos de sua história até então inconscientes ou pouco explorados.

\section{Exemplos e análises}

0 uso de entrevistas para desenvolver pesquisas cujos sujeitos são agentes sociais detentores de elevadas parcelas de capital cultural pode suscitar reações diversas e até mesmo opostas. Enquanto alguns se recusam a colaborar, sob a alegação de falta de tempo ou de interesse na participação em tal tipo de estudo, ou até ignoram a solicitação de agendamento, outros se voluntariam, com entusiasmo, para colaborar. Na investigação em pauta, os sujeitos caracterizam-se por propriedades relacionadas a alguns estados de capital cultural (BOURDIEU, 2013) na forma de uma cultura moldada pela formação acadêmica em níveis avançados - do Mestrado ao Pós-Doutorado e Livre-docência -, institucionalizada pela posse de títulos que, entre outras distinções, conferem o direito de entrada na carreira docente em nivel superior. Trata-se, portanto, de um universo de agentes que, por também serem pesquisadores em diversas áreas de conhecimento, compreendem as necessidades da entrevistadora. Apesar de se mostrarem preocupados com a preservação do anonimato, chegam a revelar francamente aspectos das trajetórias pessoais, muitos dos quais extrapolam os interesses da pesquisa, e solicitam a supressão de alguns trechos quando leem a transcrição e se arrependem da explicitação indevida.

Enfim, a "auto-hermenêutica" é praticada por sujeitos que detêm amplas condições de se comportarem conscientemente em situações de entrevista, no que tange à seleção, interpretação, ordenação e modo de exposição dos conteúdos oferecidos como dados para uma pesquisa sobre a qual todos foram informados 
previamente acerca do objeto e de seus objetivos. Tal como verificado por Michel Pollack, ao coletar depoimentos de sobreviventes de Auschwitz, entrevistas são regidas pela gestão que o sujeito realiza sobre a memória para operar a "gestão do indizivel", de acordo com o contexto e a destinação do discurso. $E$ isso depende do estabelecimento de uma relação de confiança entre os interlocutores (POLLACK, 1986).

Antes de apresentar algumas situações que ilustram o que tenho chamado de "auto- hermenêutica", vale esclarecer o que exatamente tal expressão define e como tal fenômeno se concatena aos processos de objetivação e subjetivação. Derivada do nome de Hermes, um dos deuses gregos da oratória, a palavra hermenêutica conserva até os dias atuais o significado de "arte ou técnica de interpretar e explicar um texto ou discurso". É um termo originalmente cunhado pelos estudos bíblicos (um de seus significados mais usuais é o de compreensão das Sagradas Escrituras), mas também presente na área jurídica e na filosofia, que a divide basicamente em hermenêutica epistemológica, quando aplicada à interpretação de textos, e hermenêutica ontológica, quando se interpreta uma dada realidade. Dessa divisão binária deriva várias subdivisões. A “auto-hermenêutica", destarte, pode ser considerada como uma variável da hermenêutica ontológica, por tomar como objeto de interpretação e explicação a realidade experimentada pelo próprio sujeito, que se coloca, simultaneamente, no lugar de sujeito e objeto dessa realidade. Estando nesse lugar, este sujeito é capaz de realizar uma espécie de socioanálise, como um dos instrumentos para a efetivação da "auto-hermenêutica", ou seja, erige a própria trajetória como foco da construção de sentidos relacionados a questões socio-históricas nela presentes, pois elabora e expressa não só as informações almejadas pelo entrevistador, mas também (re)organiza conteúdos que promovem a tomada de consciência sobre questões, de diversas naturezas, relativas à experiência de autoconhecimento.

A socioanálise operada na "auto-hermenêutica" sustenta-se na objetivação de si. A condição essencial para ocorrer tal objetivação é reconhecer o lugar ocupado, pois os agentes estão socialmente enraizados, em função da formação, inserção e posição, e associados à condição de classe. Reconhecendo o lugar ocupado no mundo social e no espaço acadêmico, os sujeitos podem objetivar a si e findar por descobrir o que menos estão dispostos a aceitar, quando se evidenciam os segredos do funcionamento do espaço ou, em outro exemplo, quando se descobre não estar tão bem situado ou mesmo implicado em condições desfavoráveis.

Constrói-se, assim, uma nova perspectiva condicionada pela objetivação, pois não custa lembrar que toda interpretação elaborada por um único agente só se sustenta a partir do ponto de vista no qual este agente se enuncia. Exemplo disso é a maneira como o próprio Bourdieu construiu e expôs uma "aula sobre a aula" (BOURDIEU, 1982), como um exercício de objetivação que coloca em questão o sujeito que a pratica, o que exigiu rompimentos com algumas adesões, crenças e filiações, relacionadas à origem social do cientista social que tem o papel de denunciar as representações enviesadas por esses pertencimentos.

Por outro lado, a subjetivação é um termo que tem se revestido de várias significações, principalmente na filosofia, na psicologia e na sociologia. Para fins deste trabalho, será entendido como subjetivação o processo pelo qual o agente incorpora e expressa a incorporação de elementos diversos - conhecimentos, valores, interpretações, adesões etc. - ao seu ponto de vista pessoal, mormente tornando esses elementos símbolos ou representações de si e de seus modos de pensar e viver. 
De acordo com a teoria sociológica de Pierre Bourdieu, no caso das entrevistas aqui analisadas, pode-se dizer que os movimentos paralelos e confluentes de objetivação e subjetivação, experimentados pelos participantes na pesquisa alinham-se ao postulado de que "apenas pelo fato de que nos fixamos em pensamento sobre nossa prática, que nos voltamos para ela para considerá-la, descrevê-la, analisá-la, tornamo-nos de certo modo ausentes, e tendemos a substituir o agente atuante pelo 'sujeito' reflexivo, o conhecimento prático pelo conhecimento erudito" (BOURDIEU, 2007, p. 64, aspas do autor). Aproximando-se das investigações de Pollack (1986) e das reflexões filosóficas de Paul Ricouer (1991), o material empírico que sustenta este artigo é fruto de um exercício de seleção dos fatos merecedores de exposição, o qual requer uma espécie de cisão entre o sujeito que vive e o sujeito que pensa sobre o vivido. Tal material é composto basicamente por narrativas que revelam um "eu voltado para si-mesmo", ou seja, um eu que se olha e analisa o que se olha como se fosse um outro, interpretando-se e criando uma história de e sobre si.

Passando à análise das situações de entrevista, são facilmente identificáveis as manifestações de subjetivação e objetivação. Os exemplos abundam. Há quem faça de suas primeiras palavras a assunção de que "gosto de ser cobaia" (SJC-2), ${ }^{2}$ seguida do lamento por nunca ter sido comunicado dos resultados de outras pesquisas das quais já participou. Alguns enfatizam a importância em colaborar por reconhecerem como é dificil conseguir voluntários para as próprias pesquisas, encarando a concessão da entrevista como um gesto generoso que

2 Seguindo o mesmo padrão adotado na redação da tese, os sujeitos são identificados por uma sigla correspondente ao campus onde trabalham, seguido de um número correspondente à ordem alfabética do primeiro nome de cada um. Assim, as siglas indicam os campi: Baixada Santista (BXS), Guarulhos (GRU), São José dos Campos (SJC) e São Paulo (SAO). corresponderia tanto à gratidão a todos que já os auxiliaram como a um modo de perpetuar a colaboração no meio científico. Há também quem sinta algum desconforto, quando se percebe como "objeto de estudo", como nesta passagem em que o entrevistado interpela a pesquisadora no momento em que ela confere as anotações, enquanto faz uma pergunta:

Entrevistado: [...] é estranho ser objeto de pesquisa [ri], eu acho muito estranho.

Pesquisadora: [ri] É? Você não está à vontade?

Entrevistado: Não... estou à vontade.

Pesquisadora: Estou tentando conduzir como se fosse uma conversa.

Entrevistado: Você pode conduzir, você está ótima. Eu não estou dizendo...

Pesquisadora: Você me desculpa eu ficar olhando aqui [aponta para agenda] porque são muitas informações no seu currículo...

Entrevistado: É que eu acho estranho saber que alguém ficou investigando [risos] como eu faço com as fontes, como eu faço nos meus trabalhos. Não estou dizendo que é errado. Só acho estranho. (GRU-6)

Como é impossivel apresentar detalhadamente todas as verificações de indícios de subjetivação e objetivação favoráveis à "auto -hermenêutica", ao longo da pesquisa, serão perscrutados cinco exemplos que ilustram diferentes formas e momentos de manifestação desses processos e que sustentam a afirmação de que entrevistas que exploram conteúdos autobiográficos podem surtir "efeitos colaterais", duplamente insuspeitos: ignorados, antes de ocorrerem, e indubitáveis, após serem observados.

\section{Efeito 1: "Mergulho em si" e descoberta de novas possibilidades profissionais}

Uma das entrevistadas explicitou claramente que suas declarações eram produto de um discurso previamente refletido e elaborado. Como 
já conhecia minimamente a estrutura da entrevista, houve pouco espaço para improviso e suas respostas, de fato, confirmavam o preparo prévio que favoreceu a "auto-hermenêutica": "A história é bem complexa [ri]. Eu estava pensando nisso, passei a manhã pensando nisso, falei pra você que é um mergulho mesmo esse tipo de entrevista, porque você começa a voltar em toda a sua trajetória" (GRU-2). Grande parte da entrevista girou em torno da formação universitária que carrega uma espécie de ressentimento por não ter sido integralmente trilhada em instituições públicas. A certa altura, o sujeito confidenciou:

Entrevistada: Eu não me conformei de não ter entrado na USP e vou te falar que até um ano antes de entrar na Unifesp [como docente] eu fazia várias disciplinas em várias turmas da USP. Na pós-graduação...

Pesquisadora: E o pós-doc? Vai ser na USP? [ri]

Entrevistada: Não sei... não estou com grandes expectativas. Eu quero que as minhas filhas cresçam. Eu tenho uma amiga bem íntima da Unifesp que está no Canadá. Acabou de ir pra lá. E ela levou dois filhos pequenos. $\mathrm{E}$ eu escrevo pra ela e falo que você merece muito, você é muito corajosa de ir com dois filhos pequenos para o Canadá. E ela tem uma trajetória muito parecida com a minha, assim, de escola pública, de trabalhadora. E... então, eu fico pensando.... às vezes, eu penso em fazer alguma coisa fora, mas me dá muito medo. Eu tenho uma trava ainda. Acho que por conta de toda essa trajetória da gente...

Pesquisadora: 0 idioma é um problema?

Entrevistada: Sim. Pra mim é um grande problema.

Pesquisadora: Seria o maior problema?

Entrevistada: Talvez [ri]. Eu descobri que eu tenho medo de sair do meu lugar. Eu descobri. Eu comecei a ir a congresso mais longe daqui e eu descobri que eu tenho medo [ri]. Porque antes eu culpava as crianças pequenas, o marido, eu botava várias culpas e é uma coisa minha. Eu percebi que eu tenho que elaborar melhor isso.
Pesquisadora: Quando você falou que tinha feito cinco concursos em São Paulo, eu pensei que tem alguma questão de fundo aí pra você não ter tentado em outros lugares.

Entrevistada: [...] isso eu vou ter que resolver com o terapeuta [ri]. Não está bem resolvido ainda. Eu não faria nem Sorocaba, que é aqui do lado.

\section{Pesquisadora: E teve na UFSCAR? Não teve?}

Entrevistada: humhum Não fazia... Eu descobri isso há pouco tempo. Eu comecei a fazer congresso um pouquinho mais longe, que eu tive que voar e... [...] sempre essa coisa mais interiorana [ri] [...] Mas o pós-doc não é uma coisa que me... não é uma grande meta na minha vida. Acho que é consequência só. Eu estou tão empolgada com o trabalho que eu não quero parar agora pra fazer pós-doc.

Até então, a subjetivação amalgama-se sutilmente à objetivação, à medida que o sujeito parece colocar sua trajetória diante de si e examiná-la como se houvesse uma certa distância entre aquele que vive e aquele que pensa sobre o que vive. Isso não se deve exclusivamente à situação de entrevista, embora o agente anuncie, desde o início, que dedicou parte da manhã que antecedeu o encontro para refletir sobre sua trajetória e, assim, organizar os conteúdos que seriam dignos de exposição. 0 mais valioso vem adiante. Continuando a conversa sobre a importância do Pós-Doutorado e outras experiências formativas, no contexto da Unifesp, e do meio científico brasileiro, a entrevistada conclui: "Talvez essa sua fala tenha mexido com alguma coisa dentro de mim [ri] e daqui a pouco eu vou querer fazer Pós-doc também [risos]. É aquela coisa, você tem que correr atrás" (GRU-2).

"Sua fala"? A entrevistada objetiva tão radicalmente a interação comunicativa que atribui à entrevistadora a enunciação dos conteúdos que promoveram a "auto- hermenêutica", numa espécie de projeção cujo aspecto psicanalítico não cabe aqui discutir. Tal 
comportamento pode ser relacionado à empatia decorrente da familiaridade entre os interlocutores (BOURDIEU, 2008a), tendo em vista que, mesmo sem se conhecerem previamente, a entrevistada se sente à vontade, por reconhecer propriedades que the são comuns, tais como: gênero, faixa etária e interesses acadêmicos. Nesse clima, a "auto-hermenêutica" floresce no solo da confiança na capacidade compreensiva da pesquisadora, abrindo novas perspectivas para a entrevistada refletir sobre e (re)definir os rumos a serem tomados em sua trajetória acadêmica.

\section{Efeito 2: Momento terapêutico gratuito}

Enquanto o Efeito 1 parece ter sido desencadeado horas antes da entrevista, de acordo com a declaração de que a entrevistada havia passado "a manhã pensando nisso", no Efeito 2, o sujeito parece ter sido tomado de surpresa pela avalanche de conteúdos que julgou pertinentes expor, o que fez com que o encontro numa cafeteria durasse bem mais do que o previsto, sendo uma das entrevistas mais longas (175 minutos). Houve duas interrupções. A primeira, passada a primeira meia hora, quando o marido da entrevistada veio até nós para avisar que iria aguardá-la numa livraria próxima. Quase duas horas depois, ele telefonou e ela respondeu risonhamente: "Ainda vai demorar um pouquinho. Minha vida tem muita coisa para contar, olha só até que horas estamos aqui!" (GRU-10).

Mesmo pressionadas pelo adiantado da hora, a entrevista prosseguiu sem pressa, passando inclusive por assuntos imprevistos, até que se travou o seguinte diálogo:

Entrevistada: Enfim, é isso, menina, eu te ajudei em alguma coisa? Tem aí mais coisas?

Pesquisadora: Não. Meu protocolo de questões esgotou. Você acha que tem alguma coisa que seria importante dizer e não teve oportunidade de falar?

Entrevistada: Falei tanto [ri]. Falei tanto. Você me fez pensar sobre coisas que eu nunca tinha pensado. Em questão da Unifesp. Essa coisa do pertencimento, né? Essas coisas... a gente não reflete muito. A gente vai fazendo as coisas meio no modo contínuo e não para pra pensar. (GRU-10)

Finalmente, no momento de despedida simultâneo ao acerto da conta na cafeteria, que estava prestes a fechar, a entrevistada completa: "Puxa, muito obrigada! Além de ter feito uma terapia grátis, ainda ganho um café! [...] Gostei muito de dar entrevista, é uma terapia!" (GRU-10). Enquanto percorríamos a distância até o metrô, onde nos separamos, a entrevistada insistia nos comentários sobre a validade terapêutica da participação na pesquisa, ou seja, enaltecia a oportunidade de falar sobre sua trajetória, de maneira guiada e organizada, de modo a estabelecer alguns sentidos e interpretações sobre os quais jamais houvera pensado antes.

\section{Efeito 3: Entusiasmo, concentração, inibição de apetite e planejamento de eventos}

$\mathrm{Na}$ entrevista mais longa de toda a amostra observa-se um efeito bastante particular, cuja percepção se deu a posteriori. Se não fosse uma troca de e-mails entre os interlocutores, tal efeito não teria sido identificado. 0 encontro para a coleta da entrevista estendeu-se, aproximadamente, das $11 \mathrm{~h}$ às $16 \mathrm{~h}$. Os indícios do Efeito 3 são encontrados na comunicação pessoal, a seguir, por ocasião do envio de um documento solicitado pela pesquisadora:

\section{Entrevistado:}

Patrícia, anexo o memorial. não almoçamos na terça-feira. somente percebi quando cheguei em casa... um beijo. 


\section{Pesquisadora:}

Muito obrigada pelo memorial. Eu até pensei em te convidar para almoçar, mas como você não deu sinais de estar com fome, declinei da intenção. É comum você se esquecer de comer?

\section{Entrevistado:}

[...] Falar de tantos assuntos importantes também deixou minha mente interessada no que foi discutido e não no que o estômago estava querendo. Quando sua pesquisa ficar pronta, iremos discuti-la nos campi da Unifesp. E um dia irei visitar a sua universidade para aumentar o repertório sobre as universidades públicas.

Um beijo, Patrícia. (GRU-6)

Diferente dos efeitos anteriormente apresentados, o Efeito 3 é multifacetado e só emergiu plenamente após o distanciamento dos interlocutores. As múltiplas faces podem ser sintetizadas no entusiasmo, como comandante dos conteúdos expressos na entrevista e nos projetos dela decorrentes. 0 mais curioso é que nenhum dos planos expostos na troca de e-mails havia sido aventado durante o encontro presencial, o que demonstra tratar-se de decisões tomadas após a entrevista, provavelmente desencadeadas pela subjetivação dos conteúdos tratados. Cabe acrescentar que esta foi a entrevista em que houve um maior nível de dificuldade na condução, pois o sujeito falava longamente, retomando ideias e argumentos sobre uma mesma questão, com pausas que a entrevistadora aproveitava para colocar novas questões, as quais eram ignoradas, conforme o sujeito prosseguia falando espontaneamente sobre o que ele próprio decidia ser importante, naquele momento, ainda que fugisse ao escopo das questões colocadas. Algumas perguntas foram feitas ou iniciadas três ou quatro vezes até que o sujeito as considerasse e respondesse. Isso indica um estado de concentração no próprio pensamento que, aliado às reflexões posteriores - geradoras de planos acadêmicos que passam a ter a pesquisadora como polo irradiador da ação (discutir a sua pesquisa, visitar a sua universidade) -, pode favorecer a auto-hermenêutica, não exatamente a respeito do que já se viveu, mas dos projetos acadêmicos vindouros, quer dizer, das intencionalidades de tratamento de certos temas, no interior da universidade onde atua, do interesse em conhecer a realidade de outras universidades federais etc.

Em suma, a entrevista mobilizou a organização de conteúdos, principalmente de valores e metas, que extrapolam o fim específico da colaboração acadêmica pontual numa pesquisa, ao permitir que o sujeito objetivasse e subjetivasse a sua trajetória, pregressa e porvir, ao ponto de se desinteressar pelas questões fisiologicamente vitais: "Falar de tantos assuntos importantes também deixou minha mente interessada no que foi discutido e não no que o estômago estava querendo". Vê-se, portanto, que os "efeitos colaterais" de uma entrevista de natureza autobiográfica podem repercutir em aspectos inimagináveis a priori pelo pesquisador e, quiçá, pelo próprio entrevistado. Todos eles convergindo para formas de interpretação e compreensão de si, de suas intencionalidades e de seus projetos.

\section{Efeito 4: Autocensura e desejo de compartilhamento}

O quarto efeito também ocorreu posteriormente à situação de entrevista, sendo comunicado via e-mail, logo após o sujeito ter recebido a transcrição integral de sua participação na pesquisa. Sua reação foi a seguinte: "Nossa, mas que fala gigante!!! Falo muito! rs. Deu um pouco de vontade de compartilhar a entrevista com alguns colegas. Depois de 'tratada', se puder, seria legal..." (BXS-5).

Dois aspectos merecem ser destacados neste efeito composto e aparentemente contraditório. Primeiramente, a percepção da extensão do discurso, quando observado na forma escrita. Em nenhum momento, duran- 
te o encontro presencial, o sujeito havia dado sinais de que seu relato estivesse assumindo proporções exageradas. No entanto, quando se depara com o discurso transcrito, considera a "fala gigante", e ironiza a autocrítica, ao grafar uma espécie de sigla que significa "risos" (rs) na sequência da expressão "falo muito!". Em seguida, e aí reside a aparente contradição, ele abandona subitamente o tom de autocrítica e confessa o desejo de tornar seu relato público, desde que passasse por um processo de depuração da forma escrita.

Uma intenção apresentada nesses termos só pode ter como gênese algum processo "auto-hermenêutico", que leva o sujeito a refletir sobre o que expôs acerca de sua trajetória e, por conseguinte, a avaliá-la como detentora de elevado grau de exemplaridade, o que a torna digna de compartilhamento, por ser revestida de um valor socio-histórico que, aos seus olhos, parece ser de interesse dos seus pares. Dito de outro modo, a participação na pesquisa deixa de ser, na perspectiva do sujeito, a única finalidade da entrevista, e ele passa a reivindicar que sua história seja conhecida por outros agentes situados em posições semelhantes à sua. Abrindo mão da garantia do anonimato, o sujeito subverte o propósito pelo qual seu relato foi coletado, transcrito e arquivado, após análise amparada em diretrizes éticas que impedem a divulgação da autoria do discurso, e instaura outra possibilidade de uso do material autobiográfico, que passaria a cumprir outros intentos, conforme é transformado em exemplo de autossocioanálise da trajetória de um docente em particular.

\section{Efeito 5: Autocensura e arrependimento}

O último efeito identificado diz respeito à inquietação manifestada a posteriori, por uma das entrevistadas, ao receber a transcrição integral, duas semanas após a concessão da entrevista. Em e-mail que confirma o recebimento do material, o sujeito confessa:

Entrevistada: [...] Vou me lembrar de vc sim pq falei um monte de coisas na entrevista, $\mathrm{q}$ pensando bem, nem sei se deveria ter dito... mas agora já foi e é o preço que eu pago por ser muito faladeira, depois me questiono... (ainda bem q vai ficar tudo no anonimato...) Mas foi engraçado, comecei a reler e dei muita risada do meu jeito de falar! e qdo a gente fala, tem muita coisa que fica meio desconectada..., parece meio louco. (Vai ver q sou mesmo... kkkkk). (SAO-6)

Assim como no Efeito 4, a primeira reação do sujeito é de autocensura, pela extensão e pelos conteúdos expressos que, quando apreendidos na forma escrita, podem revelar características que o sujeito atribui a si próprio, como a prolixidade, por exemplo. 0 diferencial é que BXS5 associa a natureza do seu discurso, embora autocriticado por causa da extensão, ao caráter de exemplaridade digna de compartilhamento com os pares, enquanto SAO-6 reforça a importância do anonimato para se proteger da imagem de "louco", portanto nada exemplar, que concatena à aparência "desconectada" da entrevista, segundo sua avaliação. Em ambas as situações, a apreciação das transcrições inscreve-se num processo "auto-hermenêutico" que leva o sujeito a fazer de sua trajetória objeto de socioanálise, isto é, relacionando as condições socio-históricas nas quais os feitos relatados foram possiveis, o sujeito interpreta sua trajetória com mais propriedade. 0 resultado do processo reflexivo-interpretativo pode culminar, por um lado, no desejo de expor suas venturas ou, por outro lado, na necessidade de ocultar sua identidade.

Outro aspecto importante neste quinto efeito é a oportunidade de autodescoberta que a leitura da transcrição da entrevista oferece ao sujeito. Rindo de si mesmo, o agente 
objetiva sua trajetória e, a partir da objetivação, que ocorre paralelamente à subjetivação, instrumentaliza-se para o exercício da "auto -hermenêutica". O resultado final de todo esse processo dificilmente será conhecido pelo pesquisador e, de certa forma, talvez permaneça inconsciente até mesmo para o próprio sujeito.

\section{Para concluir}

Os variados e inesperados modos de manifestação do potencial "auto-hermenêutico" conferido às situações de entrevista indicam que o ato de falar de si, mesmo que para um estranho e com finalidade específica de colaboração numa pesquisa científica, corresponde a uma oportunidade de desencadear processos de autossocioanálise, conforme o sujeito reconheça a capacidade de reelaborar alguns aspectos de sua trajetória, inclusive com vistas a reordenar os rumos com base na análise das condições reconhecidas e enunciadas. Sendo assim, a relação dos sujeitos com seus próprios relatos - seja no momento de sua enunciação oral, seja refletindo sobre o dito, após a situação da entrevista ou, ainda, apreciando a transcrição integral do seu discurso - assemelha-se daquela observada por Christine Delory-Momberger a respeito do que a autora denomina como histoire de vie:

Pode-se dizer que a história de vida é uma ficção verdadeira, no sentido em que ela inventa a realidade que pretende revelar, mas que tal invenção constitui, no momento em que se anuncia, a verdade do sujeito, em duas frentes: ela é a história que ele tem por verdadeira e ele se constrói como sujeito (individual e social) no ato de sua enunciação. Se a história da vida não é um déjà-là ao qual daria acesso o relato feito, ela aparece, em contrapartida, como um dos lugares privilegiados da invenção e da produção do sujeito na linguagem. Ato de palavra complexo que institui o sujeito no tempo onde ele se anuncia, a história de vida merece plena- mente o estatuto de ato performativo que os linguistas reconhecem aos enunciados que efetuam a ação ao mesmo tempo em que as significam. (DELORY-MOMBERGER, 2001, p. 8-9. Grifos da autora. Tradução livre).

Nesse sentido, os enunciados analisados ilustram verdades das quais o sujeito se serve, no momento mesmo da entrevista ou a posteriori, para ampliar a compreensão de si e de seus projetos acadêmicos. ${ }^{3}$ Uma vez admitida a entrevista como evento desencadeador de tal compreensão, firma-se que a "auto-hermenêutica" pode ser considerada como uma oportunidade epistêmica que se configura como uma espécie de contrapartida, na forma de lucro simbólico, pela participação na pesquisa, com dimensões subjetivas, desigualmente distribuído entre os colaboradores. Trata-se, portanto, de um processo em que o ponto de vista do sujeito se torna objetivador de si próprio, ao tomar distância de sua complexa trajetória, principalmente nas confluências das dimensões: pessoal, formativa e profissional.

Como afirmava Bourdieu (2005), objetivar o sujeito da objetivação é uma das mais delicadas e dificeis tarefas na construção do conhecimento científico. No entanto, o caráter epistemológico da "auto-hermenêutica", nas situações analisadas, não tem finalidade científica e, portanto, há de se guardar as devidas diferenças e características entre o conhecimento que o entrevistador constrói, com base no conteúdo das entrevistas, triangulado com outras fontes, e o conhecimento que o entrevistado elabora, por seu turno, à medida que objetiva sua trajetória como expressão linguística de suas vivências. Tal diferença de estatuto epistemológico faz com que a noção de objetivação não se aplique do mesmo modo aos ocupantes dos dois polos da situação de entrevis-

3 A respeito dos "atos performativos" ver a Parte II do livro A economia das trocas linguísticas (BOURDIEU, $2008 \mathrm{~b}$ ), especialmente o capítulo "A força da representação". 
ta - cada qual particularizado por um ponto de vista específico que se determina não só pelo posicionamento social de cada agente, mas também pelo papel ocupado na interlocução em pauta - e, assim, faz todo o sentido falar no processo de "auto-hermenêutica" como uma conquista do entrevistado, que se aproveita da colaboração numa pesquisa para reorganizar e reinterpretar aprendizados sobre si, a partir de experiências diversas, muitas das quais jamais estiveram sob o crivo reflexivo. Afinal, o ato de narrar a própria história é uma troca de experiência, cujo centro é ocupado por um "si-mesmo" que se faz de "outro", quando problematiza a si próprio e, realiza assim, uma “hermenêutica do si" (RICOUER, 1991).

Falar de "efeitos colaterais" de entrevistas que exploram informações autobiográficas é

\section{Referências}

BOURDIEU, Pierre. Leçon sur la leçon. Paris: Éditions de Minuit, 1982.

As regras da arte: gênese e estrutura do campo literário. Tradução Maria Lúcia Machado. 2. ed. São Paulo: Companhia das Letras, 2005.

Meditações pascalianas. Tradução Sérgio Micelli. 2. ed. Rio de Janeiro: Bertrand Brasil, 2007.

A miséria do mundo. Tradução Mateus

S. Soares Azevedo; Jaime A. Clasen; Sérgio H. de Freitas Guimarães; Marcus Antunes Penchel; Guilherme J. de Freitas Teixeira; Jairo Veloso Vargas. 8. ed. Petrópolis, RJ: Vozes, 2008a.

A economia das trocas linguísticas: 0 que falar quer dizer. Tradução Sérgio Micelli. 2. ed. São Paulo: EDUSP, 2008b.

Os três estados do capital cultural. In: NOGUEIRA, Maria Alice; CATANI, Afrânio M. (Orgs.). falar, portanto, de um potencial epistêmico metacientífico, que extrapola as pretensões do pesquisador e que oferece, às suas fontes, uma oportunidade impar de revisitar e reafirmar sua própria história. Afinal, como dizia Riobaldo: "Viver... o senhor já sabe: Viver é etecétera" (ROSA, 2001, p. 76).

Alinhavando os etecéteras das experiências que compõem as trajetórias, com o delicado fio reflexivo que somente o próprio sujeito é capaz de manejar, os agentes entrevistados demonstraram, indubitavelmente, que uma pesquisa qualitativa pode surtir efeitos ou, se preferir, resultados a priori inimagináveis e, metodologicamente, inspiradores para os pesquisadores que se empenham em produzir e problematizar a funcionalidade formativa da metodologia autobiográfica.

Escritos de Educação. 14. ed. Petrópolis, RJ: Vozes, 2013. p. 79-88.

COSTA, Patrícia Claudia da. Ilusão biográfica: a polêmica sobre o valor das histórias de vida na sociologia de Pierre Bourdieu. Revista Linhas, Florianópolis, v. 16, n. 32, p. 51-71, set./dez. 2015.

DELORY-MOMBERGER, Christine. Le récit de vie de la production à la réception: une éducation de soi. In: DELORY-MOMBERGER, Christine; HESS, Remi. Le sens de l'histoire: moments d'une biographie. Paris: Anthropos, 2001. p. 4-31.

POLLACK, Michael. La gestion de l'indicible. Actes de la recherche en sciences sociales, v. 62-63, p. 3053, juin 1986.

RICOEUR, Paul. 0 si-mesmo como um outro. Tradução de Luci Moreira Cesar. Campinas, SP: Papirus, 1991.

ROSA, João Guimarães. Grande sertão: veredas. São Paulo: Nova Fronteira, 2001. 
Patrícia Claudia da Costa e professora Adjunta da Universidade Federal de Viçosa campus Florestal, na área de Fundamentos da Educação. Doutoranda pela Faculdade de Educação da Universidade São Paulo.Ee-mail: patriciaclaudia@ usp.br.

Rodovia LMG 818, km 06 - Florestal - MG - CEP 35690-000 